ISSN 1112-9867

Available online at

http://www.jfas.info

\title{
RHEOLOGY AND SCALING BEHAVIOR OF SWELLING CLAY DISPERSIONS
}

\author{
S. Chaoui, A. Mehamha, N-H. Belkham and D. Benachour
}

Laboratory of Polymer Materials (LMPPM), Department of Engineering Process, Faculty of Engineering Science, University Ferhat ABBAS, Sétif

Received: 23 November 2012 / Accepted: 21 December 2012 / Published online: 31 December 2012

\begin{abstract}
The microstructure and scaling of rheological properties of colloidal gels of bentonite investigated as a function of volume fraction and strength of interparticle interaction over a range of volume fractions, elastic modulus is well described with a scaling law functions of volume fractions, while the role of interparticle attractions can be accounted for by expressing these rheological properties as $\left(\phi / \phi_{\mathrm{g}}-1\right)^{\mathrm{n}}$, where $\phi_{\mathrm{g}}$ captures the strength of particle interaction and $\mathrm{n}$ the microstructure.

The scaling variable $\left(\phi_{\mathrm{p}} / \phi_{\mathrm{pc}}-1\right)$, suggested in percolation theory to describe rheological behavior near percolation transition, acts to collapse $G$ ' data suggesting that along lines of constant $\left(\phi / \phi_{\mathrm{g}}-1\right)$ these gels are rheologically identical.
\end{abstract}

Keywords: rheology, scaling behavior, clay

\section{INTRODUCTION}

The state of association of colloidal suspensions depends on the nature of the interparticles interaction energy. Various conditions such as salt concentration, $p$, surfactant additives, and temperature can effect dispersion stability. Repulsive interparticles forces drive particles apart and therefore contribute to the stability. Attractive forces cause particles associations (flocculation) and are the cause of dispersion instabilities.

Author Correspondence, e-mail: salihachaoui@yahoo.fr

ICID: 1025914 
As the solids concentration increases flocculation can cause the formation of a gel. A gel is formed through the transition of a liquid sol into a space filling network structure which possesses a very high viscosity and a finite elastic modulus. Colloidal gel consists of fractal flocs formed by particle flocculation. At a critical gel volume fraction, $\phi_{\mathrm{p}}^{\mathrm{c}}$, the fractals aggregates forming in suspension begin to overlap and form a three-dimensional network causing the gel to form [1].

The flow behavior of flocculated suspensions and gels is a problem of widespread industrial and theoretical importance. Countless industrial process involves the processing of flocculated or gelled suspensions. For example, in ceramic processing the density of green particle compacts plays an important role in the final reliability of the fired ceramic. Packing density variations in a powder compact often result in nonuniform shrinkages and microstructural defects upon firing. Typically, a well dispersed suspension will lead to a dense green body. However, the ceramic slurry often contains a microstructure of particle types of different densities and if the particles are dispersed preferential sedimentation may occur. There fore, flocculated ceramic slurries of necessary strength to resist individual particle segregation are used. Higher quality compacts can be formed by controlling the degree of interparticles attraction, However, the influence that interparticle attractions have on floc structure, rearrangement under shear, and network strength are poorly understood [2].

The purpose of this paper is to interpret rheological data of bentonite dispersions using a percolation concepts.

\section{EXPERIMENTAL PROCEDURE}

The bentonite sample was obtained from Maghnia region in western part of Algeria. This has the molecular formula:

$$
\left(\mathrm{Si}_{3.8656} \mathrm{Al}_{0.1343}\right)\left(\mathrm{Al}_{1.4676} \mathrm{Fe}_{0.002} \mathrm{Mg}_{0.1415}\right) \mathrm{O}_{10}(\mathrm{OH})_{2} \mathrm{M}^{+}{ }_{0.5516}
$$

and had physical and chemical properties and mineralogical composition which were almost identical to a reference material described in a previous paper. Dispersions were prepared by weighting bentonite powder then Nacl salt and complete at $100 \mathrm{~g}$ of distillated water.

The weigh concentration obtained spread between 5 and $15 \%$ w/w for bentonite and between 0.01 and $0.9 \% \mathrm{w} / \mathrm{w}$ for the salt.

Samples were stirring at high speed for $48 \mathrm{~h}$ (best homogenization), at room temperature.

The equilibrium concentration of exchangeable cations in the electrolyte of bentonite dispersions was $1.6 .10^{-3}$ mol.L $\mathrm{L}^{-1}$. These dispersions had a $\mathrm{pH}$ of 8.34 to 7.29. 
The rheological measurements; were carried out with a HAAKE RS100 controlled stress rheometer at $25^{\circ} \mathrm{C}$.Before the measurements the suspensions were allowed for 1 hour at $25^{\circ} \mathrm{C}$.

The storage (elastic) modulus G' and the loss modulus G', obtained from oscillatory experiments are reliable values only in case the structure of the system is not disrupted during The oscillating deformation. In the most cases the system showed the linear viscoelastic behavior below a deformation $\gamma=0.1$ at an oscillation frequency of $1 \mathrm{~Hz}$.

In the frequency test that followed the modulus $G$ ' and $G$ ', were measured with increasing frequency at $\gamma=0.025$.

\section{RESULTATS AND DISCUSSION}

The results clearly show that the level of elastic modulus $G^{\prime}$ is nearly independent on frequency and is much higher that of the loss modulus G', This behavior is characteristic of an elastic gel-like structure[3].

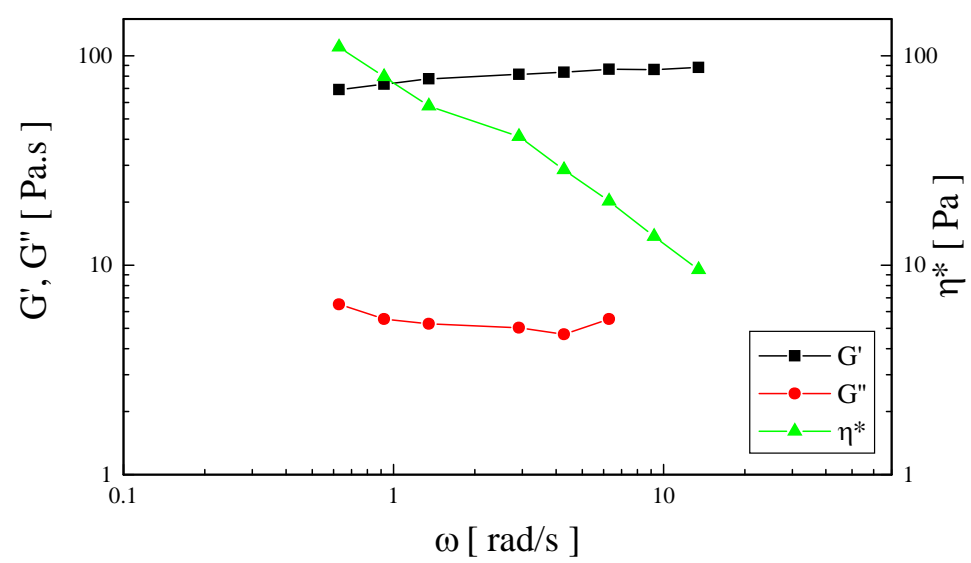

Fig.1. Dynamic Response of clays dispersions for $\gamma=0.025, \mathrm{C}_{\mathrm{sel}}=0.5 \% \mathrm{w} / \mathrm{w}, \mathrm{C}_{\mathrm{ben}}=12 \% \mathrm{w} / \mathrm{w}$

Figure (II) show the dependence of G' on the particle volume fraction.. From these results, a critical concentration at which elasticity of the suspension appears is observed for all suspensions.

The purpose of rheology in oscillation mode is to better include/understand the evolution of clay dispersions with the bentonite concentration for different salt concentration. One understands by "structure", an association of particles inter-connected in a three-dimensional continuous network likely to transmit elastic forces in response to a deformation [4]. G' is the rheological function best adapted to the characterization of structure in elastic matter. 


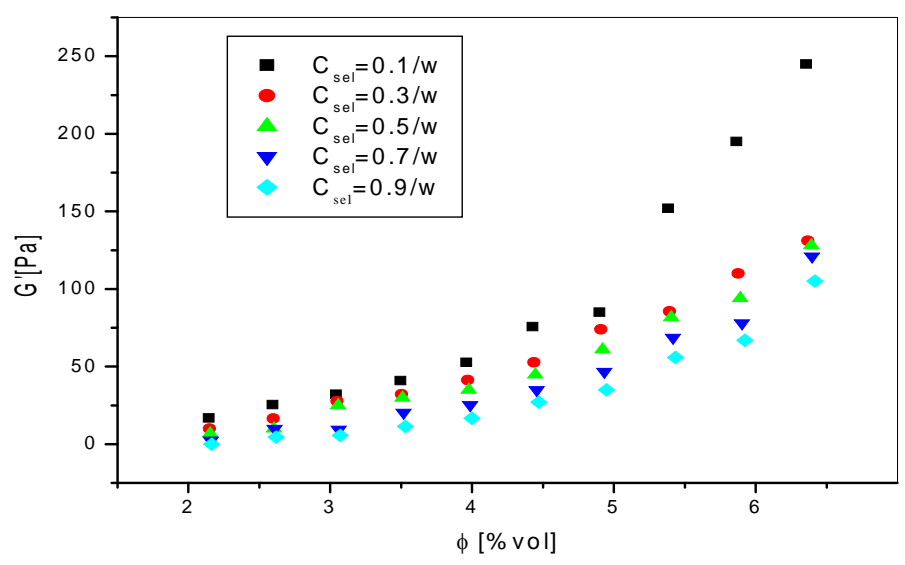

Fig.2. Evolution of elastic modulus G' vs the volume fraction

Experimental measurements show that $\mathrm{G}^{\prime}$ is null with the weak bentonite concentrations then increases with bentonite concentration, then increases above a critical volume fraction of bentonite such as:

- $\mathrm{G}^{\prime}=0$ pour $\phi_{\mathrm{p}}<\phi_{\mathrm{p}}^{\mathrm{c}}$

- $\mathrm{G}^{\prime} \neq 0$ pour $\phi_{\mathrm{p}}>\phi_{\mathrm{p}}^{\mathrm{c}}$

These threshold values $\left(\phi_{p}^{c}\right)$ are obtained from linear extrapolation from the first point to zero elastic modulus.

Table 1. Evolution of critical volume fraction

\begin{tabular}{cccccc}
\hline $\mathbf{C}_{\text {sel }}(\% \mathbf{p d s})$ & 0.1 & 0.3 & 0.5 & 0.7 & 0.9 \\
\hline$\phi_{\mathbf{p}} \mathbf{c}(\boldsymbol{\%}$ vol $)$ & 1.27 & 1.55 & 1.75 & 1.93 & 2.16 \\
\hline$\phi_{\mathbf{p}} \mathbf{t}^{\mathbf{t}}$ \% vol $)$ & 4.22 & 4.41 & 4.54 & 4.72 & 4.84 \\
\hline
\end{tabular}

According to [4], the transport of the elastic forces of one end with other of sample, i.e. to saying, between the plate and the cone of the rheometer, implies existence of continuous network of inter-connected aggregates. However, an increase in the salt concentration causes a reduction in aggregates volume. Because of this contraction, the network becomes increasingly compact as the salt concentration increases. Thus, for a quantity of bentonite given, the module $G^{\prime}$ decrease when the salt concentration increases. When the number of discontinuity is too significant. It is thus necessary increasing the quantity of bentonite to compensate for the reduction in aggregates volume and to restore $G^{\prime} \neq 0$, where an increase of $\phi_{\mathrm{p}}^{\mathrm{c}}$ with salt. 


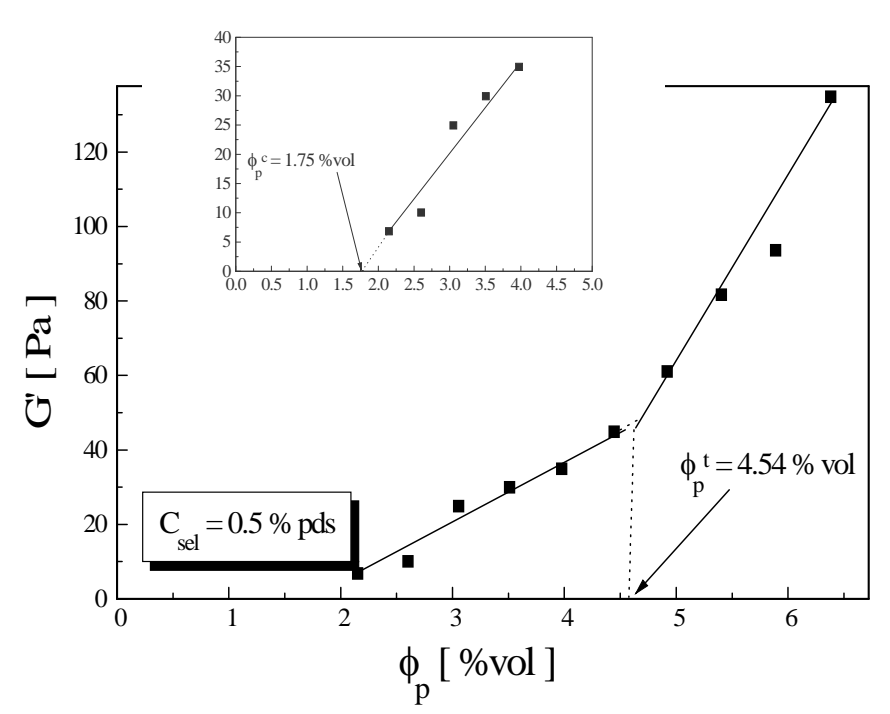

Fig.3. Determination of a critical volume fraction $\Phi^{\mathrm{p}} \mathrm{c}$ and $\mathrm{Ppt}$ for different concentrations in salt

In summary, We are in face of a problem of conduction on a network associated with the existence of critical concentrations. It seems, thus that a modeling of the percolation type can be planned to explain the variation of the elastic module with the bentonite concentration within a framework more general. If it is the case, scaling law must be established in preamble with any attempt at modeling.

\section{Scaling law}

In the framework of this study, the scaling laws used are expressed according to the volume fraction of bentonite $\phi_{\mathrm{P}}(\mathrm{p}$ for bentonite particle) defined by the transformation of the mass concentration into volume concentration according to the following equation:

$$
\begin{array}{cc}
\phi(\% \text { vol })=\frac{V_{\text {ben }}}{V_{\text {tot }}} \times 100=\frac{1}{1+\frac{\rho_{\text {ben }} m_{\text {eau }}}{m_{\text {ben }} \rho_{\text {eau }}}} \times 100 & \\
\mathrm{~V}_{\text {ben }}=\mathrm{m}_{\text {ben }} / \rho_{\text {ben }} & \rho_{\text {ben }}=2.4 \mathrm{~g} \cdot \mathrm{cm}^{-3} \\
\mathrm{~V}_{\text {tot }}=\mathrm{V}_{\text {ben }}+\mathrm{V}_{\text {eau }} & \rho_{\text {eau }}=1.0 \mathrm{~g} / \mathrm{cm}^{-3}
\end{array}
$$

In the field of the studied volume fractions $(2.144<\phi<6.418)$, the evolution of $G^{\prime}$ as a fonction of $\phi$ highlights two fractions volumes indicating two structural transitions volume fraction, $\phi_{p}{ }^{c}$ the critical volume fraction in particle measured at the threshold of percolation, $\phi_{\mathrm{p}}{ }^{\mathrm{t}}$ the volume fraction in particles which indicates a second structural transition, and will be discussed within the framework of the scaling laws[5,6]. 
Table I represents the influence of the ionic force on the values of $\phi_{p}{ }^{c}$ and $\phi_{p}{ }^{t}$, an increase in the salt concentration involves an increase in $\phi_{\mathrm{p}}{ }^{\mathrm{c}}$ and $\phi_{\mathrm{p}}{ }^{\mathrm{t}}$.

The fundamental units which regroup and form a sample spanning cluster during recovery are flocs. Further more, if the flocs regroup randomly in space, this behavior can be viewed as an elastic site percolation problem[4]. To make use of this analogy, flocs must be identified with sites present in the elastic network. Thus according to Eq:

$$
\begin{aligned}
& \mathrm{G}^{\prime} \sim\left(\phi_{\mathrm{p}} / \phi_{\mathrm{p}}{ }^{\mathrm{c}}-1\right)^{\mathrm{s}} \\
& \mathrm{G}^{\prime} \sim\left(\phi_{\mathrm{p}} / \phi_{\mathrm{p}}^{\mathrm{c}}\right)^{\mathrm{p}} \ldots
\end{aligned}
$$
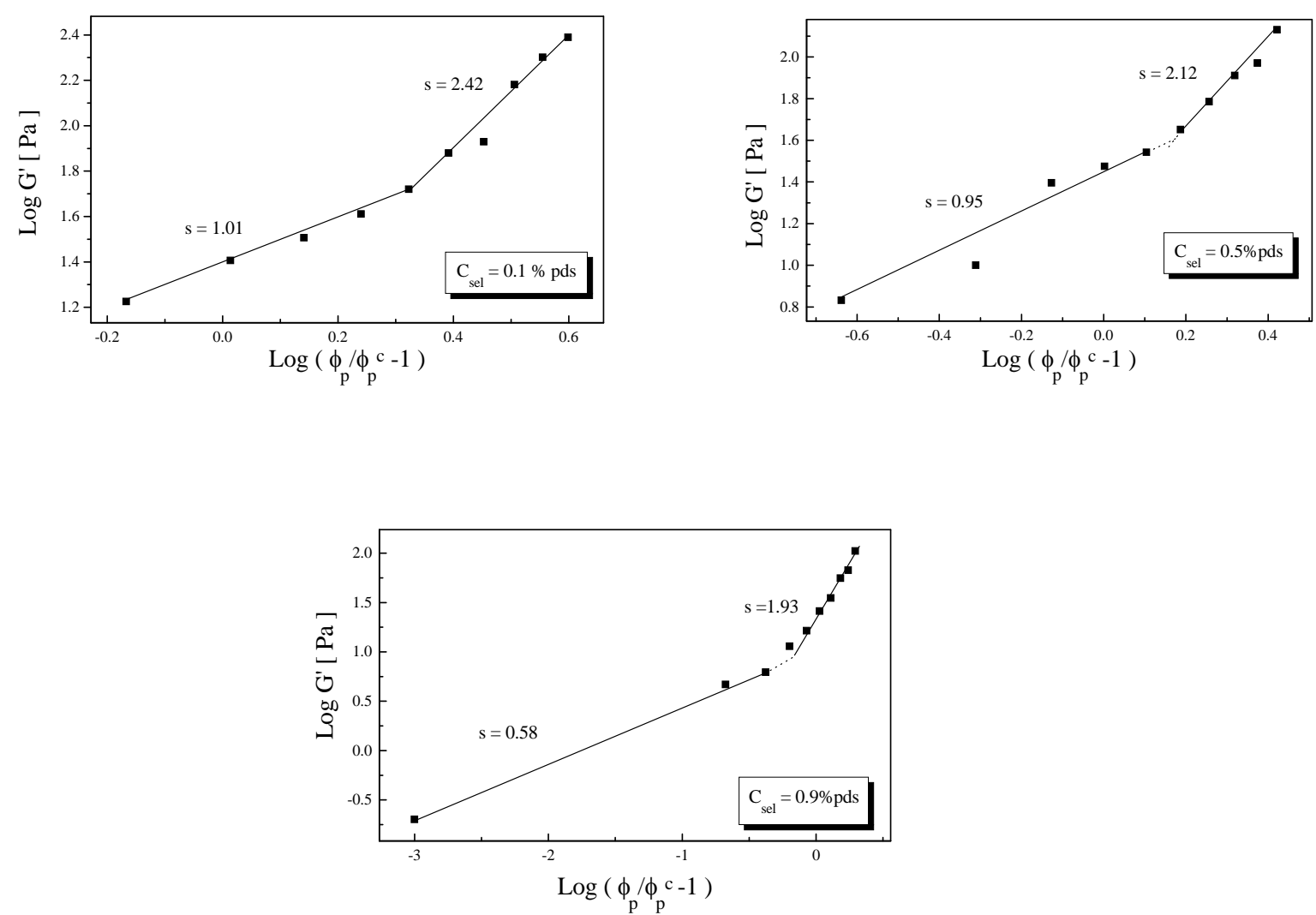

Fig.3. Critical exposants for $\mathrm{G}^{\prime} \sim\left(\phi_{\mathrm{p}} / \phi_{\mathrm{p}}{ }^{\mathrm{c}}-1\right)$ for given salt concentration

Where $\phi_{\mathrm{p}}$ is the volume fraction bentonite particles and $\phi_{\mathrm{p}}{ }^{\mathrm{c}}$ is the volume fraction at the percolation threshold.

The critical exponent $\mathrm{s}$ and $\mathrm{p}$ were calculated from graphs of $\log \mathrm{G}^{\prime} \mathrm{vs} \cdot \log \left(\phi_{\mathrm{p}} / \phi_{\mathrm{p}}{ }^{\mathrm{c}}-1\right)$ and $\log \mathrm{G}^{\prime}$ vs. $\log \left(\phi_{\mathrm{p}} / \phi_{\mathrm{p}}{ }^{\mathrm{c}}\right)$.Such graphs are presented in FIG. 3.

Two observations could be made from the results shown in FIG. 3: 
1) All of the cases studied show a dependence of $G^{\prime}$ on $\left(\phi_{p} / \phi_{p}{ }^{c}-1\right)$ of kind of Eq.(1).

2) The system exhibit two regions with different exponents s, i.e., a low concentration region with a small exponent $\mathrm{s}$, and a higher concentration region with a larger exponent $\mathrm{s}$.

The behavior of $G^{\prime}$ with $\left(\phi_{p} / \phi_{p}{ }^{c}-1\right)$ described in point (2) above can be interpreted as a $\phi_{p}{ }^{t}$ is a transition from a bond-shear percolation zone to rigidity percolation zone where tensile-bond forces dominate $\left(\phi_{\mathrm{p}}{ }^{\mathrm{t}}\right.$ is determined by the same manner as the $\left.\phi_{\mathrm{p}}{ }^{\mathrm{c}}\right)$.

Graphs of $\log G^{\prime}$ vs. $\log \left(\phi_{\mathrm{p}} / \phi_{\mathrm{p}}^{\mathrm{c}}\right)$.do not present the two zones of percolation.

\section{MASTER CURVES}

Above the percolation threshold, the increase of the particle concentration increases the number of particles taking part in the formation of structure of network. The percolation of the clusters allows the constraint to be transmitted through the network and consequently to carry out the conditions necessary for the measurement of elasticity according to the volume fraction. The scaling law suggested, make it possible to make predictions on the mechanics and the distribution of the size of the flocs beyond the percolation threshold [2]. Figure 4 illustrate the main curves of the scaling law used. The scaling law $G^{\prime}$ on $\left(\phi_{p} / \phi_{p}{ }^{c}-1\right)$ seems to give a better correlation of the data where those data are almost to gather along one line. This behavior indicates that these systems are rheologiquelly identical, and probably related to some details microstucturals
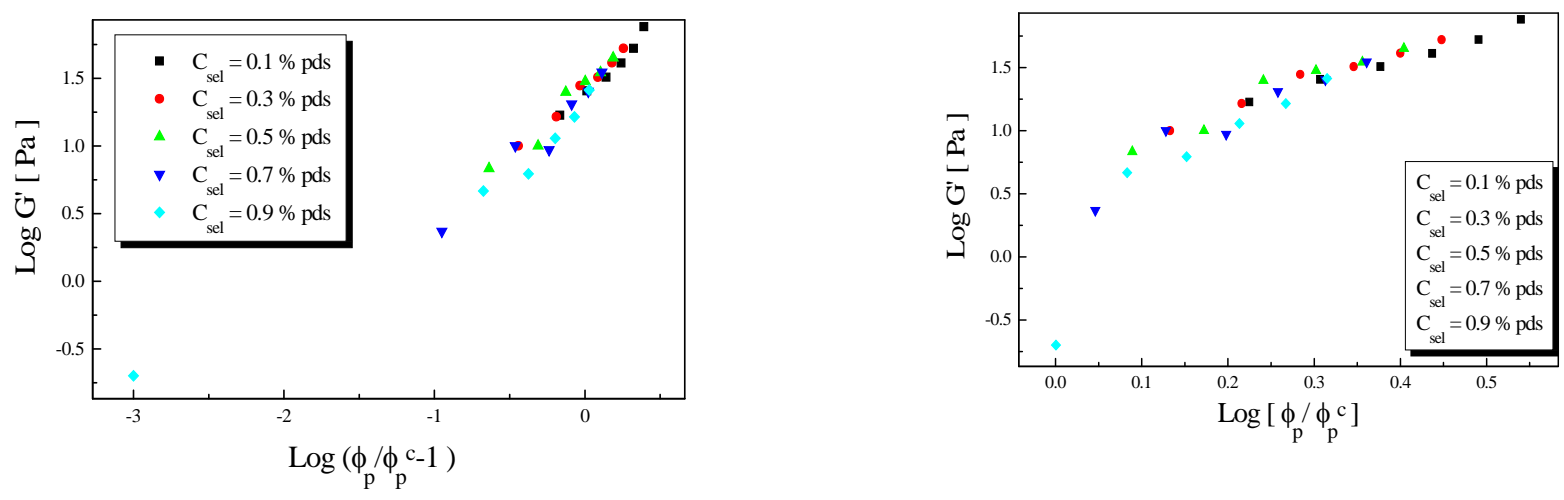

Fig.4. Master curves for $\mathrm{G}^{\prime} \sim\left(\phi_{\mathrm{p}} / \phi_{\mathrm{p}}{ }^{\mathrm{c}}-1\right)^{\mathrm{s}}$ and $\mathrm{G}^{\prime} \sim\left(\phi_{\mathrm{p}} / \phi_{\mathrm{p}}{ }^{\mathrm{c}}\right)^{\mathrm{p}}$ 


\section{CONCLUSION}

It has been shown that the use of percolation concepts can be useful in understanding the rheology of concentrated suspensions. Moreover, with this approach we are able to interpret rheological data.

Concepts taken from the percolation theory allowed us to connect the evolution of the properties of transport of dispersions by scaling laws to their structural organization in the microscopic scale according to the composition of the components of the system. These Laws, of forms $\mathrm{G}^{\prime} \sim\left(\phi_{\mathrm{p}} / \phi_{\mathrm{p}}{ }^{\mathrm{c}}-1\right)^{\mathrm{s}}$ and $\mathrm{G}^{\prime} \sim\left(\phi_{\mathrm{p}} / \phi_{\mathrm{p}}{ }^{\mathrm{c}}\right)^{\mathrm{p}}$ are carried very general and characteristic of critical phenomena (phase transition, transition ground-freezing).

For studied clay dispersions, the exponents $\mathrm{s}$ and $\mathrm{p}$ change from a value around 1 for weak bentonite concentrations up to values higher than 2 for high concentrations. This shows the change of mechanism conditioned by transverse forces to a mechanism whose central forces are dominant. Critical exponents seem to decrease with the ionic strength.

Mistresses' curves show that our system is rheologically identical, i.e. the scale and distribution of flocs on dispersions are the same.

\section{REFERENCES}

[1] C.J.Rueb ,C.F.Zukoski, Rhéology of Suspension of Weakly Attractive Particules Approach to Gelation, Journal of Rheology, vol.42, N6, pp.1451-1476, (1998).

[2] C.J.Rueb, Flow Properties of Colloidal Gel, thesis, Illinois univ., (1994).

[3] Dau, J.; Lagaly, G. Surface Modification of Bentonites .II.Modification of Montmorillonite with Cationic (Polyethylen Oxides). CCACAA., vol.71, $N^{\circ} 4$, pp.983-1004. (1998).

[4] H.Kanai, R.C.Navarrete, C.W.Macosko, L.E.Sacriven, Fragile Networks and Rheology of Concentrated Suspensions, Rheol Acta, vol.31,pp.333-344, (1992).

[5] G.M.Channel,C.F.Zukoski, Shear and Compressive Rheology of Aggregated Alumina Suspension, AICHE Journal, vol.43, N7, pp.1700-1780, (1997).

[6] P. Cassagnau, Melt rheology of organocly and fumed silica nanocomposites; Polym., vol.49, $\mathrm{N}^{\circ} 1,(2008)$, pp.1-14.

\section{How to cite this article}

Chaoui S, Mehamha A, Belkham N-H and Benachour D. Rheology and scaling behavior of swelling clay dispersions. J Fundam Appl Sci. 2012, 4(2), 202-209. 